\title{
Reduced Socs 3 expression in adipose tissue protects female mice against obesity-induced insulin resistance
}

\author{
R. Palanivel • M. D. Fullerton • S. Galic • J. Honeyman • \\ K. A. Hewitt • S. B. Jorgensen • G. R. Steinberg
}

Received: 9 April 2012 / Accepted: 18 June 2012 / Published online: 8 August 2012

(C) Springer-Verlag 2012

\begin{abstract}
Aims/hypothesis Inflammation in obesity increases the levels of the suppressor of cytokine signalling-3 (SOCS3) protein in adipose tissue, but the physiological importance of this protein in regulating whole-body insulin sensitivity in obesity is not known.

Methods We generated Socs3 floxed (wild-type, WT) and Socs 3 aP2 (also known as Fabp4)-Cre null (Socs3 AKO) mice. Mice were maintained on either a regular chow or a high-fat diet (HFD) for 16 weeks during which time body mass, adiposity, glucose homeostasis and insulin sensitivity were assessed.

Results The HFD increased SOCS3 levels in adipose tissue of WT but not Socs 3 AKO mice. WT and Socs 3 AKO mice had similar body mass and adiposity, assessed using computed tomography (CT) imaging, irrespective of diet or sex. On a control chow diet there were no differences in insulin sensitivity or glucose tolerance. When fed a HFD, female but not male Socs 3 AKO mice had improved glucose tolerance as well as lower fasting glucose and insulin levels
\end{abstract}

Electronic supplementary material The online version of this article (doi:10.1007/s00125-012-2665-3) contains peer-reviewed but unedited supplementary material, which is available to authorised users.

R. Palanivel $\cdot$ M. D. Fullerton $\cdot$ G. R. Steinberg $(\bowtie)$

Division of Endocrinology and Metabolism,

Department of Medicine, McMaster University,

1280 Main St West,

Hamilton, ON, Canada L8N $3 Z 5$

e-mail: gsteinberg@mcmaster.ca

S. Galic · J. Honeyman - K. A. Hewitt - S. B. Jorgensen •

G. R. Steinberg

St Vincent's Institute of Medical Research

and Department of Medicine, University of Melbourne,

Melbourne, Australia

S. B. Jorgensen

Diabetes Research Unit, Novo Nordisk A/S,

Maaloev, Denmark compared with WT littermates. Hyperinsulinaemic-euglycaemic clamps and positron emission tomography (PET) imaging demonstrated that improved insulin sensitivity was due to elevated adipose tissue glucose uptake. Increased insulin-stimulated glucose uptake in adipose tissue was associated with enhanced levels and activating phosphorylation of insulin receptor substrate-1 (IRS1).

Conclusions/interpretation These data demonstrate that inhibiting SOCS3 production in adipose tissue of female mice is effective for improving whole-body insulin sensitivity in obesity.

Keywords Adipocyte protein 2 (aP2/FABP4) · AMPK . Glucose homeostasis - Immunometabolism - Inflammation • Insulin receptor substrate $\cdot$ Leptin $\cdot$ Macrophage $\cdot$ Suppressor of cytokine signalling (Socs-3) · Tumour necrosis factor (TNF)

$\begin{array}{ll}\text { Abbreviations } \\ \text { ACC } & \text { Acetyl-CoA carboxylase } \\ \text { AMPK } & \text { AMP-activated protein kinase } \\ \text { aP2 } & \text { Adipocyte protein } 2 \\ \text { CT } & \text { Computed tomography } \\ \text { ER } \alpha & \text { Oestrogen receptor alpha } \\ \text { FABP4 } & \text { Fatty acid binding protein } 4 \\ \text { FDG } & {\left[{ }^{18} \text { F]Fluorodeoxyglucose }\right.} \\ \text { GDR } & \text { Glucose disposal rate } \\ \text { GINF } & \text { Glucose infusion rate } \\ \text { GTT } & \text { Glucose tolerance test } \\ \text { HFD } & \text { High-fat diet } \\ \text { IKK } & \text { Inhibitor } \text { KB kinase } \\ \text { IRS1 } & \text { Insulin receptor substrate-1 } \\ \text { IS-GDR } & \text { Insulin-stimulated glucose disposal rate } \\ \text { JNK } & \text { c-Jun terminal kinase } \\ \text { LPS } & \text { Lipopolysaccharide } \\ \text { PET } & \text { Positron emission tomography } \\ \text { RER } & \text { Respiratory exchange ratio }\end{array}$




\section{SOCS Suppressor of cytokine signalling}

Socs3 AKO Socs3 Ap2-Cre null

SUV Standard uptake value

WT Wild-type

\section{Introduction}

Adipocytes and resident macrophages are a critical source of inflammatory cytokines that cause metabolic abnormalities including the development of insulin resistance. The suppressor of cytokine signalling (SOCS) family of proteins are negative regulators of cytokine signalling that act via their central SH2 domain and conserved C-terminal SOCS box to modulate inflammatory responses [1]. In obese rodents, SOCS3 is upregulated in hypothalamus [2, 3], liver [4], skeletal muscle [5, 6] and adipose tissue [7, 8]. In humans, SOCS3 abundance is also increased in mononuclear cells in response to pro-inflammatory conditions such as obesity [9] and a high-fat diet (HFD) [10], which may have important implications for adipose tissue inflammation. SOCS3 has been shown to be important for the regulation of insulin sensitivity, as it inhibits tyrosine phosphorylation of the insulin receptor [11, 12] and insulin receptor substrate-1 (IRS1) $[4,12]$ and may also target IRS proteins for proteasomal degradation [13]. Importantly, in-vitro studies indicate that SOCS3-deficient adipocytes derived from mouse embryonic fibroblasts are protected against the development of TNF- $\alpha$-induced insulin resistance [14].

In addition to its role in regulating insulin sensitivity, SOCS3 has also been shown to be important for regulating sensitivity to leptin. Bjorbaek et al were the first to demonstrate that SOCS3 binding to Y985 of the leptin receptor inhibited leptin activation of the signal transducer and activator of transcription-3 in hypothalamic nuclei $[15,16]$. Both Socs 3 hypothalamic specific null mice [2] and Socs 3 mice with haploinsufficiency [17] have enhanced leptin sensitivity and are resistant to diet-induced obesity. Similarly, the overproduction of SOCS3 in proopiomelanocortin neurons induces glucose intolerance and obesity [18]. In addition female, but not male, mice with a point mutation at Y985 within the leptin receptor are protected against developing diet-induced obesity and insulin resistance [19]. In adipocytes, leptin has been shown to increase the activity of AMP-activated protein kinase (AMPK) resulting in increased phosphorylation of its downstream substrate acetyl-CoA carboxylase (ACC) [20]. This activation of AMPK is associated with the rapid depletion of lipid from adipocytes and results in increases in glycerol but not NEFA, suggesting that leptin reduces adipose tissue mass by increasing the rate of adipose tissue fatty-acid oxidation $[21,22]$. Consistent with the potential for SOCS3 to inhibit adipose tissue leptin signalling, recent reports in both rodents [23] and humans [24] have found that AMPK phosphorylation is reduced with obesity.

Evaluating the physiological importance of SOCS3 in vivo has been difficult because $\operatorname{Socs} 3^{-/-}$mice die mid gestation due to placental insufficiency [25]. In adipocytes the transgenic overexpression of Socs 3 in adipose tissue by greater than 100-fold reduces adipose tissue but not wholebody insulin sensitivity when mice are fed a standard chow diet [26]. However, when mice were fed an HFD, the overexpression of Socs 3 in adipose tissue prevented the development of HFD-induced obesity [26]. This result was attributed to a reduction in adiposity of HFD-fed Socs 3 transgenic mice, increased secretion of adiponectin and subsequently elevated levels of mitochondrial enzymes in skeletal muscle [26]. While these studies suggest an important but surprising role for adipose tissue SOCS3 in regulating whole-body energy metabolism, an important caveat is that given the functional redundancy of the SOCS family of proteins and their relatively low abundance in the absence of overt inflammation, this supra-physiological increase in SOCS3 might be expected to overlap with other SOCSrelated signalling pathways [25]. For example, SOCS1 shares $\sim 85 \%$ homology with SOCS3 and has also been shown to inhibit insulin signalling $[4,13,27]$. Therefore, it is feasible that the phenotype of these transgenic mice might be a function of inhibiting multiple pathways simultaneously and thus may not be indicative of the physiological role of SOCS3 in adipose tissue following modest increases in production (two- to threefold) as observed with obesity $[8,11]$.

The generation of Socs 3 floxed mice has made it possible to study the tissue-specific effects of $\operatorname{Socs} 3$ deletion. In the liver the deletion of $\operatorname{Socs} 3$ enhances insulin sensitivity in mice fed a chow diet; however, when fed an HFD, deletion of Socs 3 promotes the development of fatty liver disease, systemic inflammation and obesity [28, 29]. In the current study we generated Socs 3 Ap2-Cre null mice (Socs3 AKO). We show that Ap2-Cre deletion of Socs 3 does not alter body mass or adiposity, and that female, but not male, Socs 3 AKO mice were partially protected against the development of obesity-induced glucose intolerance and insulin resistance due to enhanced adipose tissue insulin sensitivity.

\section{Methods}

Animal procedures All procedures were approved by $\mathrm{St}$ Vincent's Hospital and McMaster University Animal Ethics Committee. Mice were generated by crossing Socs 3 floxed mice generated on a C57B16 background [30] with mice expressing Cre-recombinase under the control of the $a P 2$ (also known as Fabp4) promoter [31] that had been backcrossed onto a C57B16 background for seven generations. Socs $3^{\text {flox/flox }} \mathrm{Cre}^{-/-}$(wild-type, WT) and Socs $3^{\text {flox/flox }} a P 2$ - 
$\mathrm{Cre}^{+/-}$(Socs3 AKO) mice were maintained on a $12 \mathrm{~h}$ lightdark cycle with lights on at 07:00 hours. For lipopolysaccharide (LPS) experiments female and male WT and Socs 3 AKO mice were injected with $2 \mathrm{mg} / \mathrm{kg}$ LPS (Invivogen, San Diego, CA, USA) and tissues harvested $2 \mathrm{~h}$ later as described [29]. For diet experiments WT and Socs3 AKO littermates starting at 6 weeks of age were maintained on chow, or an HFD (digestible energy of $17 \mathrm{MJ} / \mathrm{kg}$ with $46 \%$ of energy from fat) for 16 weeks [29]. Body mass was monitored weekly. Energy expenditure and activity levels were measured using a Columbus Instruments Laboratory Animal Monitoring System (Columbus, OH, USA) over $72 \mathrm{~h}$ as described [32, 33]. Glucose tolerance tests were performed after 15 weeks of chow or high-fat feeding through intraperitoneal injection of mice with $1 \mathrm{~g} / \mathrm{kg}$ glucose (Sigma-Aldrich, Oakville, ON, Canada) in saline and were followed by monitoring of tail-blood glucose (Bayer, Leverkusen, Germany) [29, 34]. Euglycaemic-hyperinsulinaemic clamps were conducted in conscious mice as recently described [29, 32, 34]. Briefly, 3 days before application of the clamp two catheters were inserted into the right jugular vein. The clamp was conducted after a $6 \mathrm{~h}$ fast (which commenced at the start of the light-cycle), in restrained conscious mice that had been acclimatised to the restrainers for the preceding 3 weeks. At $60 \mathrm{~min}$, a solution containing D- $\left[3-{ }^{3} \mathrm{H}\right]$ glucose was infused at a constant rate $(278 \mathrm{Gbq} / \mathrm{h}, 0.12 \mathrm{ml} / \mathrm{h})$ for $1 \mathrm{~h}$ for determination of basal glucose turnover. At $0 \mathrm{~min}$, insulin diluted in saline was infused at a rate of $10 \mathrm{mU} \mathrm{kg}^{-1} \mathrm{~min}^{-1}$ and a $50 \%$ dextrose solution was infused at a variable rate to maintain euglycaemia. Once steady state was achieved, glucose specific activity was measured in whole blood after deproteinisation with $\mathrm{BaOH}$ and $\mathrm{ZnSO}_{4}$. Hepatic glucose production and glucose disposal rate for the basal and clamp period were calculated using Steele's equation for steady-state conditions.

In vivo glucose uptake and body composition $\left[{ }^{18} \mathrm{~F}\right]$ Fluorodeoxyglucose (FDG) was synthesised at McMaster University by the nucleophilic substitution method using an FDG synthesising instrument (GE Healthcare, Milwaukee, WI, USA) and a cyclotron (Siemans20-30 gb) [35]. After an $8 \mathrm{~h}$ fast mice were injected with insulin $(0.5 \mathrm{U} / \mathrm{kg})$ diluted in $0.9 \%$ physiological saline and $5 \mathrm{~min}$ later received an intravenous administration of FDG (10.8 \pm $1.2 \mathrm{MBq} / \mathrm{g}$ ) [35]. After injection, the mice were maintained under conscious conditions and warmed using a heating pad. At $28 \mathrm{~min}$ post insulin injection mice were anaesthetised with isofluorane and at $30 \mathrm{~min}$ small-animal positron emission tomography (PET; Philip Mosaic, Andover, MA, USA) and micro-computed tomography (CT) (Gamma Medica-Ideas Xspect System, Northridge, CA, USA) imaging were performed using an acquisition time of $15 \mathrm{~min}$ for PET, followed by CT for $5 \mathrm{~min}$ [35]. Images were reconstructed using 3D-RAMLA algorithm, with no attenuation correction and no correction for partial-volume effects of the tomograph as previously described [35]. Quantification was performed by region-of-interest analysis using Amide Research Workplace software and FDG tissue uptake calculated using the mean value of standard uptake values (SUV) as described [35]. Analysis of total body fat composition was carried out using Amira software (Visage Imaging; www.amira.com/downloads.html) and the mean value of voxels of segmented adipose were calculated as described [32].

Serum hormones and cytokines analysis Whole blood was spun at 7,000 $\mathrm{g}$ for $5 \mathrm{~min}$ at $4^{\circ} \mathrm{C}$ and the serum removed. Leptin, resistin, TNF- $\alpha$ and IL- 6 were measured in serum by BioPlex assay (Millipore, Burlington, ON, Canada), NEFA via colorimetric assay (Wako Chemical, Richmond, VA, USA) and adiponectin (Millipore) via ELISA, all following the manufacturers' recommendations.

Real-time quantitative PCR Adipose tissue macrophages were isolated from gonadal adipose tissue following collagenase digestion (Liberase enzyme; Roche, Mannheim, Germany) and isolated using a Mouse CD11b Positive Selection kit (Stemcell Technologies, Vancouver, BC, Canada) as described [32]. Adipose tissue macrophages and gonadal adipose tissue were then lysed in TRIzol-reagent (Invitrogen, Carlsbad, CA, USA) and RNA extracted for real-time quantitative PCR as described [36].

Immunoblotting Protein lysates were generated from epididymal fat pads homogenised in ice-cold buffer $(50 \mathrm{mmol} / 1 \mathrm{HEPES}$, pH 7.4, $150 \mathrm{mmol} / \mathrm{l} \mathrm{NaCl}, 10 \mathrm{mmol} / \mathrm{l} \mathrm{NaF}, 1 \mathrm{mmol} / \mathrm{l}$ sodium pyrophosphate, $0.5 \mathrm{mmol} / 1 \mathrm{EDTA}, 250 \mathrm{mmol} / 1$ sucrose, $1 \mathrm{mmol} / 1$ dithiothreitol, $1 \%$ (vol./vol.) Triton $\mathrm{X}-100,1 \mathrm{mmol} / 1 \mathrm{Na}_{3} \mathrm{VO}_{4}$ and one Roche protease inhibitor tablet per $50 \mathrm{ml}$ buffer) using an electrical homogeniser [36]. Protein content in lysates was measured by the BCA method (Pierce, Rockford, IL, USA) and immunoblotting was conducted using antibodies (Cell Signaling Technology, Danvers, MA, USA) against total and/or phosphorylated forms of SOCS3, the insulin receptor substrate-1 (Y1122), Akt (T308 and S473), IKK (S176/180) and JNK (T183/Y185) as described [36]. AMPK and ACC antibodies were generated and used as described [37]. Bands were visualised using an enhanced chemiluminescence system (Vilber Fusion-FX1; Eberhardzell Germany) and quantified using Scion image software.

Calculations and statistical analysis Data are presented as the mean \pm SEM and were analysed using Student's $t$ test or, where appropriate, one-way repeated measures or two-way ANOVA with a Bonferroni post-hoc test (GraphPad PRISM, 
version 4.0; La Jolla, CA, USA). Differences were considered statistically significant at $p<0.05$.

\section{Results}

Socs3 AKO mice develop similar degrees of obesity Two hours after the injection of LPS, Socs 3 expression was observed in adipose tissue of WT but not Socs 3 AKO mice thus indicating the effective deletion of SOCS3 from adipose tissue of Socs 3 AKO mice (see electronic supplementary material [ESM] Fig. 1). Starting at 6 weeks of age, mice were either maintained on a control chow diet or switched to an HFD. When mice were fed a chow diet white adipose tissue Socs 3 mRNA expression was at the limits of detection of our real-time quantitative PCR assay ( $\sim 35$ cycles $)$ and hence we were unable to detect any difference in expression between WT and Socs 3 AKO mice. After 16 weeks of HFD feeding there was a fourfold upregulation of $\operatorname{Socs} 3$ mRNA expression in adipose tissue of WT but not Socs3 AKO mice (Fig. 1a). SOCS1 shares $\sim 85 \%$ homology with SOCS3 and has also been implicated in the inhibition of insulin sensitivity. However, SOCS1 abundance was not altered by diet or genotype in adipose tissue (data not shown). aP2 has also been shown to be produced in macrophages [38] but in contrast to our findings in adipocytes we found that expression of Socs 3 mRNA in adipose tissue macrophages of HFD-fed mice was similar between WT and Socs 3 AKO mice (ESM Fig. 2). This finding is consistent with several recent reports demonstrating that the efficiency of aP2-Cre recombination in macrophages is much less efficient than in adipocytes [39-41].

We monitored body mass over 16 weeks in both male and female Socs 3 AKO mice relative to WT littermates, fed chow or HFD. As anticipated the HFD led to significant increases in body mass in both male and female mice but
Fig. 1 Improved glucose tolerance in female Socs $3 \mathrm{AKO}$ mice. (a) Adipose tissue Socs 3 mRNA in WT (white bars) and Socs3 AKO mice (black bars) following 16 weeks consumption of a chow or HFD. Body mass of female (b) and male (c) WT (white symbols) and Socs 3 AKO mice (black symbols) fed chow (circles) or HFD (triangles, inverted triangles). (d) Glucose tolerance $(1 \mathrm{~g} / \mathrm{kg}$ body mass $)$ and (e) AUC ( $\mathrm{mmol} / 1 \times \min )$ in female WT and Socs 3 AKO mice fed a chow or HFD for 16 weeks. AU, arbitrary units. Data are mean \pm SEM, $n=6$ for real-time quantitative PCR data and $n=14-16$ for body mass and GTT data. ${ }^{\dagger} p<0.0001$ relative to chow control; ${ }^{*} p<0.05,{ }^{* * *} p<0.0001$ relative to WT for same diet
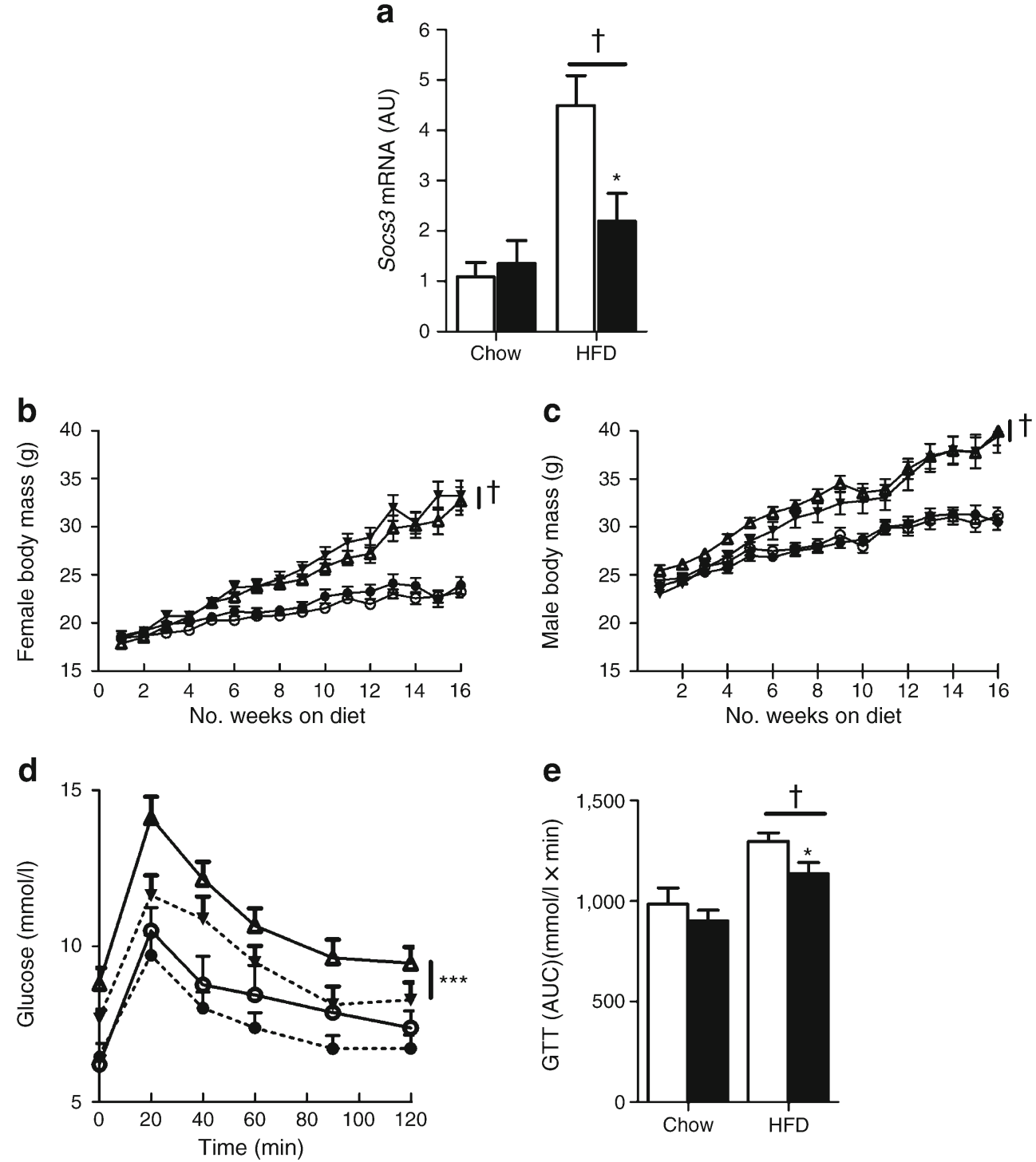
there were no differences between genotypes (Fig. 1 b, c). We next assessed glucose tolerance in male and female WT and Socs 3 AKO mice. When fed a chow diet there were no differences in glucose tolerance in either female (Fig. $1 \mathrm{~d}$, e) or male mice (ESM Fig. 3 a, b). When fed an HFD, female (Fig. 1 d, e) but not male (ESM Fig. 3 a, b) Socs 3 AKO mice had improved glucose tolerance. Given this sexual dimorphism the remainder of the analyses were completed in only female mice.
Socs3 AKO mice have similar adiposity, adipose-tissue cell size SOCS3 has been proposed to be a negative regulator of leptin signalling in adipocytes [8]; consistent with this idea, recent studies have shown that AMPK activity is reduced in adipose tissue with obesity $[23,24]$. We hypothesised that AMPK activity might be elevated in adipose tissue of Socs 3 AKO mice and that this might be associated with reductions in adipose-tissue cell size. Using CT imaging we assessed total adiposity and found that there was no difference
Fig. 2 Adiposity, adipose tissue cell size and adiposetissue AMPK activity is not altered in Socs3 AKO mice. (a) Body fat composition assessed by $\mathrm{CT}$ analysis (representative image with quantification). (b) Adipose tissue histology (haematoxylin and eosin [H\&E] stain) from WT and Socs 3 AKO mice fed chow and HFD (representative image with quantification of adipose-tissue cell size). Phosphorylation of AMPK T172 (c) and ACC S79

(d) in adipose tissue from WT and Socs 3 AKO mice fed chow or HFD. White bars, WT mice; black bars, Socs 3 AKO mice. AU, arbitrary units. Data are means \pm SEM, $n=6-8$. ${ }^{\dagger} p<0.001$ relative to chow control a

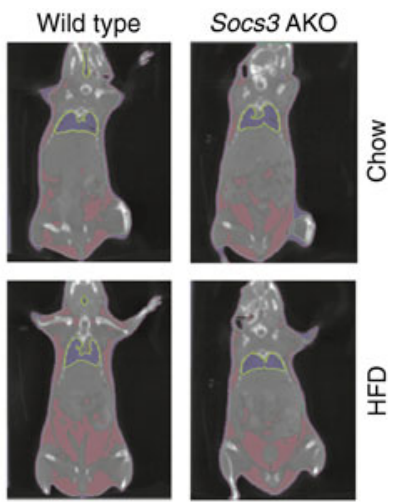

b
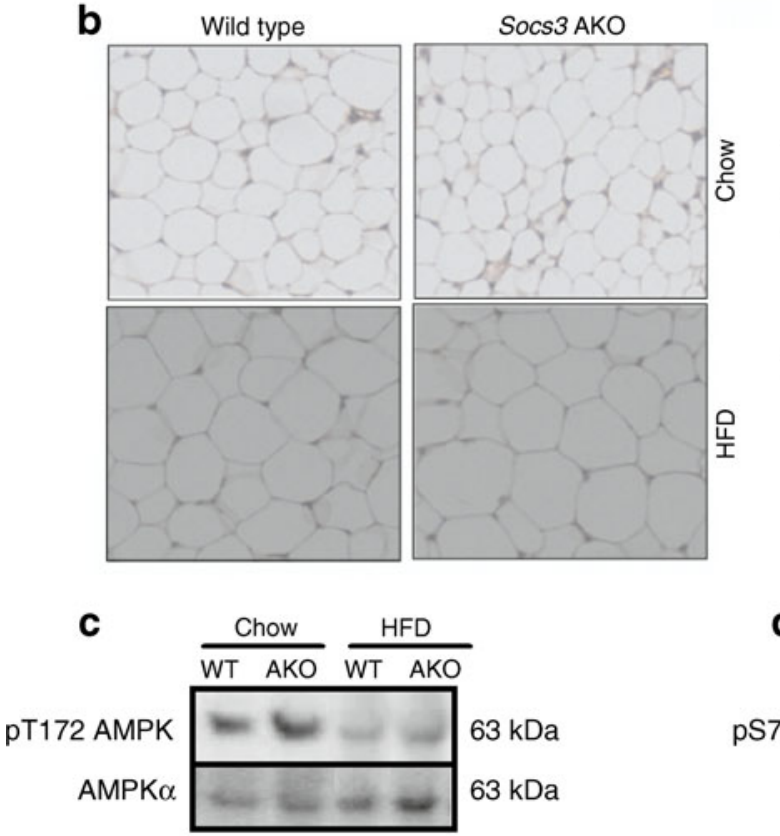

$63 \mathrm{kDa}$

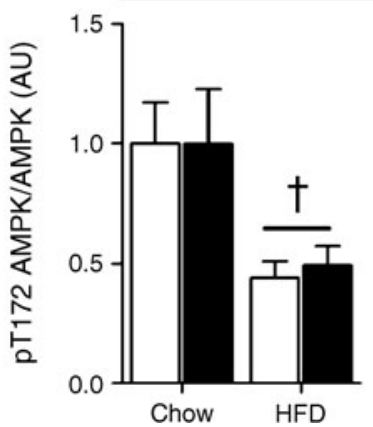

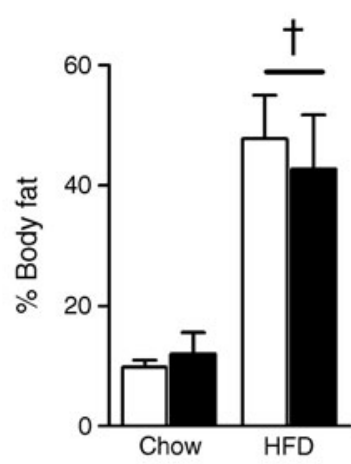
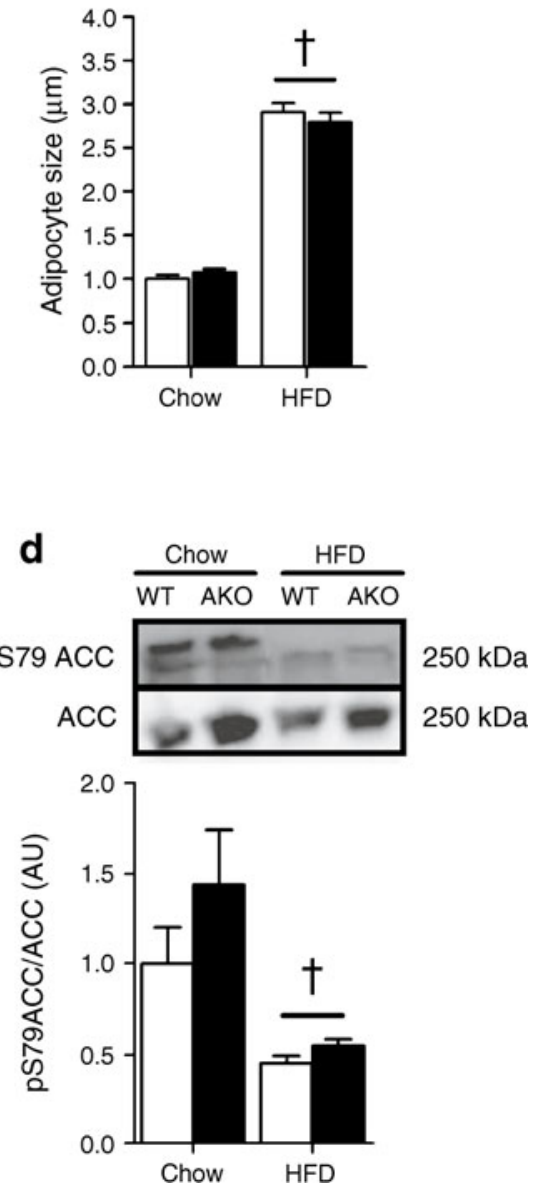
between genotypes when mice were fed chow or an HFD (Fig. 2a). Similarly, while the HFD increased mean adipocyte cell size compared with chow controls there was no difference between WT and Socs3 AKO mice (Fig. 2b). We found that, consistent with previous reports, AMPK T172 (Fig. 2c) and ACC Ser 79 (Fig. 2d) phosphorylation were dramatically reduced with the HFD but that the reduction in AMPK signalling was comparable between WT and Socs3 AKO mice. These data suggest that adipose tissue Socs 3 expression is not a critical regulator of adipose tissue morphology and that AMPK signalling is not maintained in adipose tissue of obese mice despite the absence of Socs3.

Socs3 AKO mice do not have altered energy balance or substrate use The transgenic overexpression of Socs 3 in adipose tissue using the aP2-Cre promoter results in mice that have altered rates of energy expenditure and metabolism, an effect which is attributed to altered secretion of adiponectin [26]. We found that, consistent with comparable adiposity between genotypes, serum levels of adiponectin and resistin did not differ between WT and Socs 3 AKO mice (Table 1). Surprisingly, leptin levels were lower in Socs3 AKO mice fed a chow diet but were elevated to a similar degree when mice were fed an HFD (Table 1). Serum levels of TNF- $\alpha$ were not altered by either diet or genotype (Table 1). In contrast, serum IL-6 was significantly increased in HFDfed Socs3 AKO mice (Table 1).

The transgenic overexpression of Socs 3 in adipose tissue increases oxygen consumption, activity level and food intake when mice are fed an HFD [26]. However, we found that, consistent with similar adiposity and body mass, energy expenditure, activity level and food intake were similar in WT and Socs3 AKO mice irrespective of diet (Table 2). Socs 3 has also been shown to be important in regulating substrate use and in particular has been shown to play a role in regulating fatty acid oxidation and lipogenesis [6, 26, 29]. As anticipated the HFD significantly reduced the respiratory exchange ratio (RER), indicating reduced glucose use, however, there was no difference between genotypes (Table 2). These data indicate that adipose tissue Socs 3 does not play a critical role in regulating whole-body energy metabolism.
Female Socs 3 AKO mice have improved adipose tissue insulin sensitivity when fed an HFD Improved glucose tolerance in female HFD-fed Socs3 AKO mice (Fig. 1), was associated with significantly lower fasting blood glucose (Fig. 3a) and serum insulin levels (Fig. 3b). To examine whether improvements in insulin sensitivity were related to changes in hepatic or peripheral insulin sensitivity we conducted hyperinsulinaemic-euglycaemic clamps. We did not clamp chow-fed mice as we did not detect any differences in blood glucose, serum insulin or glucose tolerance. Serum glucose concentrations before and during the clamp did not differ between WT and Socs3 AKO mice (Table 3). We found that $\operatorname{Socs} 3 \mathrm{AKO}$ mice tended to have a slightly higher glucose infusion rate (GINF) $(\sim 10 \%, p=0.12$, Table 3$)$, which was due to a $\sim 20 \%$ increase in insulin-stimulated glucose disposal rate (IS-GDR) (Table 3). There were no changes in hepatic glucose output or per cent suppression of hepatic glucose production when comparing genotypes (Table 3). To determine whether increased IS-GDR in Socs3 AKO mice involved skeletal muscle or adipose tissue we injected mice with insulin $(0.5 \mathrm{U} / \mathrm{kg})$ and measured FDG uptake using PET imaging. We found that FDG uptake was significantly higher in adipose tissue $(+56 \%, p=0.002)$ but not in muscle of Socs 3 AKO mice relative to WT littermates (Fig. 3c). Brown adipose tissue FDG uptake was also comparable between WT and Socs 3 AKO mice (WT, 4.63 \pm 0.45 ; Socs3 AKO, 4.12 \pm 0.24 SUV). Taken together these data indicate that improved insulin sensitivity in HFD-fed Socs 3 AKO mice was due to enhanced insulin-stimulated glucose disposal into white adipose tissue.

Socs3 AKO mice have enhanced adipose tissue IRS1 production and phosphorylation To assess the mechanisms contributing to the increased adipose tissue glucose uptake in HFD-fed Socs 3 AKO mice we measured total production and phosphorylation of proximal and distal components of the canonical insulin signalling pathway, 2 min after a bolus of insulin $(0.5 \mathrm{U} / \mathrm{kg})$. We found that the HFD significantly reduced IRS1 level in WT mice, but that this inhibitory effect was completely inhibited in Socs 3 AKO mice (Fig. 4 $\mathrm{a}, \mathrm{b})$. In addition, Socs 3 AKO mice were also protected from
Table 1 Serum variables following an overnight fast in female WT and Socs3 AKO mice fed a chow or HFD

Data are means \pm SEM for $n=8$ mice

$* p<0.05$ relative to $\mathrm{WT}$ littermates fed the same diet; ${ }^{\dagger} p<0.05$ relative to chow-fed controls of the same genotype

\begin{tabular}{lccccc}
\hline Variable & \multicolumn{2}{l}{ Chow } & & \multicolumn{2}{l}{ HFD } \\
\cline { 2 - 3 } \cline { 5 - 6 } & WT & Socs3 AKO & & WT & Socs3 AKO \\
\hline NEFA $(\mathrm{mEq} / \mathrm{l})$ & $2.09 \pm 0.10$ & $2.13 \pm 0.17$ & & $1.69 \pm 0.11$ & $1.54 \pm 0.24$ \\
Leptin $(\mathrm{pg} / \mathrm{ml})$ & $654 \pm 281$ & $131 \pm 33^{*}$ & & $1,916 \pm 793 \dagger$ & $1,547 \pm 595 \dagger$ \\
Adiponectin $(\mu \mathrm{g} / \mathrm{ml})$ & $18.9 \pm 2.5$ & $15.3 \pm 0.9$ & & $15.4 \pm 0.9$ & $17.7 \pm 0.9$ \\
Resistin $(\mathrm{pg} / \mathrm{ml})$ & $1,243 \pm 111$ & $1,154 \pm 84$ & & $1,729 \pm 147 \dagger$ & $1,656 \pm 317 \dagger$ \\
TNF $(\mathrm{pg} / \mathrm{ml})$ & $5.47 \pm 0.72$ & $4.92 \pm 0.74$ & & $4.46 \pm 0.78$ & $4.63 \pm 0.58$ \\
IL-6 $(\mathrm{pg} / \mathrm{ml})$ & $14.61 \pm 8.76$ & $3.47 \pm 0.62$ & & $13.10 \pm 3.70$ & $23.87 \pm 6.61 \dagger$
\end{tabular}


Table 2 Oxygen consumption, spontaneous activity levels (beam breaks in X, Y and Z directions), caloric intake and RER in chow and HFD-fed female WT and Socs3 AKO mice

\begin{tabular}{|c|c|c|c|c|c|c|c|c|}
\hline \multirow[t]{3}{*}{ Variable } & \multicolumn{4}{|l|}{ Chow } & \multicolumn{4}{|l|}{ HFD } \\
\hline & \multicolumn{2}{|l|}{ WT } & \multicolumn{2}{|l|}{ Socs 3 AKO } & \multicolumn{2}{|l|}{ WT } & \multicolumn{2}{|l|}{ Socs3 AKO } \\
\hline & Dark & Light & Dark & Light & Dark & Light & Dark & Light \\
\hline$\dot{V} \mathrm{O}_{2}\left(\mathrm{ml} \mathrm{kg}^{-1} \mathrm{~h}^{-1}\right)$ & $3,563 \pm 143$ & $2,845 \pm 92$ & $3,323 \pm 155$ & $2,708 \pm 130$ & $3,348 \pm 224$ & $2,700 \pm 172$ & $3,747 \pm 117$ & $2,940 \pm 79$ \\
\hline Activity (breaks/12 h) & $16,522 \pm 2,321$ & $3,184 \pm 571$ & $17,017 \pm 3,188$ & $4,207 \pm 936$ & $17,465 \pm 4,046$ & $2,877 \pm 937$ & $25,866 \pm 3,022$ & $4,409 \pm 426$ \\
\hline Food intake (kj/12 h) & $24.1 \pm 1.00$ & $10.8 \pm 0.67$ & $25.0 \pm 1.46$ & $12.6 \pm 1.00$ & $26.7 \pm 2.93$ & $14.6 \pm 2.05$ & $29.3 \pm 1.67$ & $15.8 \pm 1.42$ \\
\hline $\operatorname{RER}\left(\dot{V} \mathrm{CO}_{2} / \dot{V} \mathrm{O}_{2}\right)$ & $0.92 \pm 0.007$ & $0.86 \pm 0.094$ & $0.93 \pm 0.015$ & $0.88 \pm 0.019$ & $0.80 \pm 0.014$ & $0.79 \pm 0.012$ & $0.81 \pm 0.005$ & $0.80 \pm 0.007$ \\
\hline
\end{tabular}

Data are means \pm SEM, $n=8$ over $12 \mathrm{~h}$ dark and light cycles collected over a $72 \mathrm{~h}$ period

$\dot{V} \mathrm{O}_{2}$, oxygen consumption; $\dot{V} \mathrm{CO}_{2}, \mathrm{CO}_{2}$ production

an HFD-induced reduction in IRS1 Y1222 phosphorylation, as phosphorylation of this site on IRS1 was greater than in HFD-fed WT littermates even when corrected for the higher level of IRS1 (Fig. 4 a, b). Increases in IRS1 production and phosphorylation were associated with enhanced Akt T308 (Fig. 4c) and S473 (Fig. 4d) phosphorylation in HFD-fed Socs 3 AKO mice. There was also a tendency for Akt phosphorylation to be increased in Socs 3 AKO mice fed a chow diet (Fig. 4 c, d). Consistent with our data demonstrating that skeletal muscle FDG uptake was not altered in Socs 3 AKO mice, we found that IRS1 and Akt phosphorylation in muscle were not different between genotypes (data not shown). These data suggest that SOCS3 inhibits adipocyte insulin-stimulated glucose uptake via both reduction in IRS1 production and inhibition of IRS1 tyrosine phosphorylation.

In adipose tissue of obese mice the inhibitor $\mathrm{kB}$ kinase (IKK) and c-Jun terminal kinase (JNK) inhibit insulin signalling via IRS1 [42, 43]. To examine whether improved adipose tissue insulin sensitivity in Socs3 AKO mice might involve the downregulation of these pathways, we examined activating phosphorylation of IKK and JNK. We found that while as expected the HFD significantly increased adipose tissue JNK (Fig. 4e) and IKK (Fig. 4f) phosphorylation there were no differences between genotypes.

\section{Discussion}

The precise regulation of both the magnitude and duration of cytokine signalling is essential for the orchestration of many biological processes. Studies in mouse models of SOCS3 deficiency have shown an important role for this protein in the control of cytokine responses within the central nervous system [2, 17] and the liver [44]. Adipose tissue is the largest source of fuel in the body, and is also an important source of secreted proteins and inflammatory cytokines which are critical for controlling whole-body energy metabolism and insulin sensitivity [45]. In the current study we detected no change in adipose tissue cell size or total adiposity between WT and Socs 3 AKO mice when fed either a control chow or HFD. Previous studies from the Unger laboratory have shown that chronically elevated levels of leptin reduce adipose tissue cell size potentially by increasing the phosphorylation of AMPK and ACC in adipocytes and that this effect is blocked when mice become obese; findings which correlate with increases in adipose tissue SOCS3 production [20]. However, we found that even despite higher leptin levels in HFD-fed mice, AMPK and ACC phosphorylation were reduced in both WT and Socs 3 AKO mice relative to lean chow-fed controls. These data suggest that SOCS3 is not the only regulator of AMPK activity in adipocytes and that potentially other negative regulators of leptin signalling, such as protein tyrosine phosphatase 1B [46], may also be important in regulating this response.

It was previously shown that transgenic overexpression of Socs 3 in adipose tissue increased oxygen consumption and reduced appetite, resulting in reduced body mass when mice were fed an HFD. This surprising effect was attributed to the smaller adipose-tissue cell size of HFD-fed Socs $3-a P 2$ transgenic mice that resulted in increased adiponectin production and muscle mitochondrial biogenesis [26]. In the current study, we did not observe any evidence for a role of $a P 2$ deletion of Socs 3 in regulating energy balance as both WT and Socs 3 AKO mice had similar activity levels, food intake and energy expenditure and, consistent with this, similar body mass, adiposity and adiposetissue cell size. Similarly, adiponectin levels and muscle insulin sensitivity were not altered in Socs3 AKO mice. The level of $\operatorname{Socs} 3$ overexpression observed in 

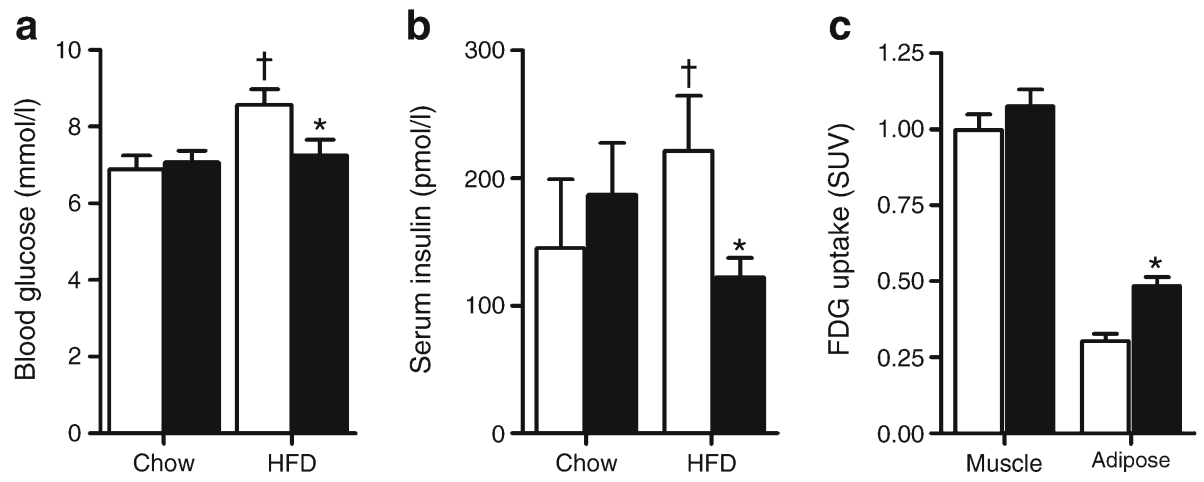

Fig. 3 Improved whole-body insulin sensitivity and increased FDG uptake in adipose tissue of Socs 3 AKO mice. (a) Reduced fasting glucose and (b) insulin levels in HFD-fed Socs 3 AKO mice. (c) Increased insulin-stimulated FDG uptake into adipose tissue but

Socs 3 aP2 transgenic mice was much higher than observed in obesity, therefore the results may have been due to overlap with Socs1, which was not altered in our model. Taken together these data suggest that it is unlikely that adipose tissue $\operatorname{Socs} 3$ is important in regulating whole-body energy balance.

In the current study we demonstrated that under normal chow-fed conditions there is no difference in whole-body glucose tolerance or insulin sensitivity between WT and Socs 3 AKO mice. This finding is consistent with the very low levels of SOCS3, which were indistinguishable between WT and Socs 3 AKO mice. However, when made obese through chronic high-fat feeding which increased SOCS3 production by approximately fourfold in adipose tissue of WT but not Socs 3 AKO mice, female but not male Socs 3 AKO mice were partially protected from developing HFD-induced glucose intolerance and insulin resistance. The reason for this sexual dimorphism is not known, but the findings are consistent with previous findings in SOCS3deficient models $[2,17]$ or leptin receptor Y985 mutant mice [19] where female, but not male mice, display more robust differences in leptin sensitivity. The findings are also very similar to those previously reported not muscle of Socs 3 AKO mice fed an HFD. White bars, WT mice; black bars, Socs 3 AKO mice. Data are mean \pm SEM, $n=12-16$ for blood glucose and insulin, $n=6$ for FDG uptake. ${ }^{\dagger} p<0.05$ relative to chow control; ${ }^{*} p<0.05$ relative to WT for same diet

in Tlr4 knockout mice, where only females were partially protected against the development of HFDinduced insulin resistance [47]. As both TLR4 and SOCS3 are important regulators of cytokine signalling these data may suggest that in male mice factors independent of inflammatory signalling are more critical for controlling insulin and leptin sensitivity in obesity. Alternatively, as oestrogen receptor $\alpha(\mathrm{ER} \alpha)$ is phosphorylated at Y737 [48] and oestrogen has been shown to upregulate SOCS3 in hepatocytes [49], it is possible that SOCS3 may also be a negative regulator of oestrogen signalling. Hence the removal of this negative regulator in female Socs3 AKO mice may allow oestrogen to more fully activate insulin sensitising pathways [50]. Future studies examining the interaction between SOCS3 and ER $\alpha$ are warranted.

Hyperinsulinaemic-euglycaemic clamps and measurements of glucose uptake using PET revealed that improvements in whole-body insulin sensitivity in Socs3 AKO female mice were due to increased rates of FDG entry into adipose tissue. We found that SOCS3 was critical for mediating HFD-induced suppression of adipose tissue IRS1 production and Y1122 phosphorylation. Importantly, this enhanced IRS
Table 3 Hyperinsulinaemiceuglycaemic clamp variables in female HFD-fed WT and Socs 3 AKO mice

Data are means \pm SEM, $n=5$ HGO, hepatic glucose output

\begin{tabular}{|c|c|c|c|}
\hline Variable & WT & Socs 3 AKO & $p$ value \\
\hline Pre-clamp glucose $(\mathrm{mmol} / \mathrm{l})$ & $6.0 \pm 0.48$ & $4.8 \pm 0.66$ & 0.083 \\
\hline Clamp glucose (mmol/l) & $5.8 \pm 0.15$ & $6.1 \pm 0.18$ & 0.10 \\
\hline Clamped GINF (mg kg ${ }^{-1} \min ^{-1}$ ) & $57.0 \pm 1.43$ & $64.4 \pm 5.36$ & 0.12 \\
\hline Basal GDR (mg kg $\left.{ }^{-1} \min ^{-1}\right)$ & $25.6 \pm 1.55$ & $23.9 \pm 4.89$ & 0.36 \\
\hline Clamped GDR (mg kg $\left.{ }^{-1} \min ^{-1}\right)$ & $62.8 \pm 2.7$ & $68.1 \pm 4.2$ & 0.14 \\
\hline IS-GDR (clamped-basal) $\left(\mathrm{mg} \mathrm{kg}^{-1} \mathrm{~min}^{-1}\right)$ & $34.3 \pm 2.5$ & $42.2 \pm 2.07$ & 0.022 \\
\hline Clamped HGO (mg kg $\left.{ }^{-1} \min ^{-1}\right)$ & $5.5 \pm 0.81$ & $4.78 \pm 0.16$ & 0.30 \\
\hline$\%$ Suppression of HGO & $77.9 \pm 3.8$ & $82.1 \pm 6.9$ & 0.22 \\
\hline
\end{tabular}


Fig. 4 Increased adipose tissue IRS 1 content and

phosphorylation in HFD-fed Socs3 AKO mice despite normal increases in JNK and IKK phosphorylation. (a, b) Adipose tissue IRS1 production and IRS1 Y1222 phosphorylation, (c) Akt (Thr308) and (d) Akt (Ser473) phosphorylation in adipose tissues of WT and Socs 3 AKO mice fed a chow or HFD following a bolus of insulin. Phosphorylation of JNK (e) and IKK (f) in adipose tissue of WT and Socs 3 AKO mice fed a chow or HFD. AU, arbitrary units. Data are mean \pm SEM, $n=8 .{ }^{\dagger} p<0.05$ relative to chow control; $* p<0.05$ relative to WT for same diet a

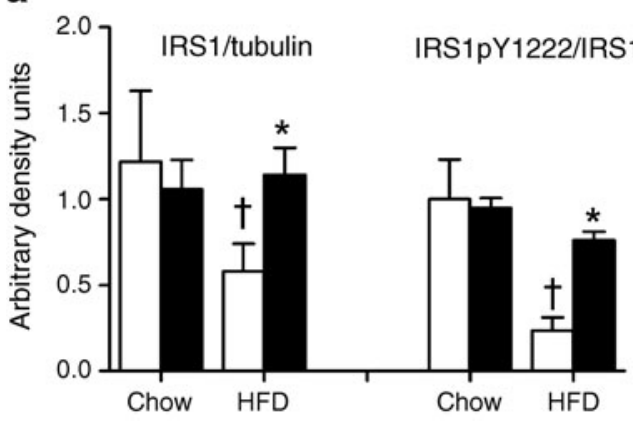

C
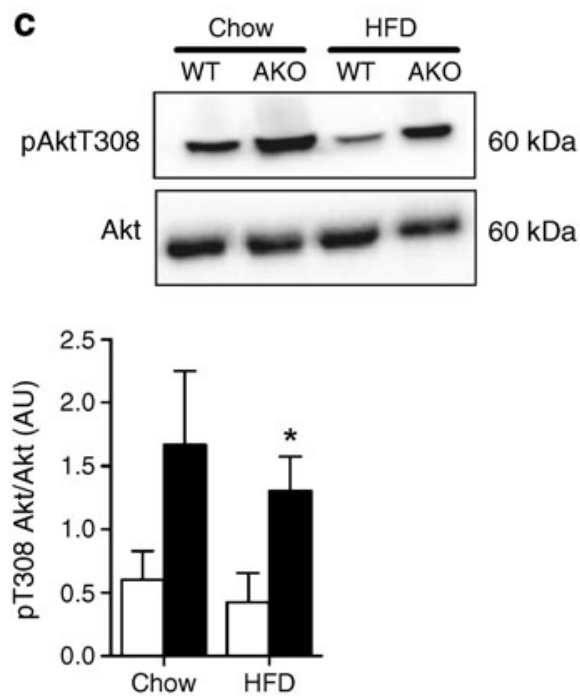

e
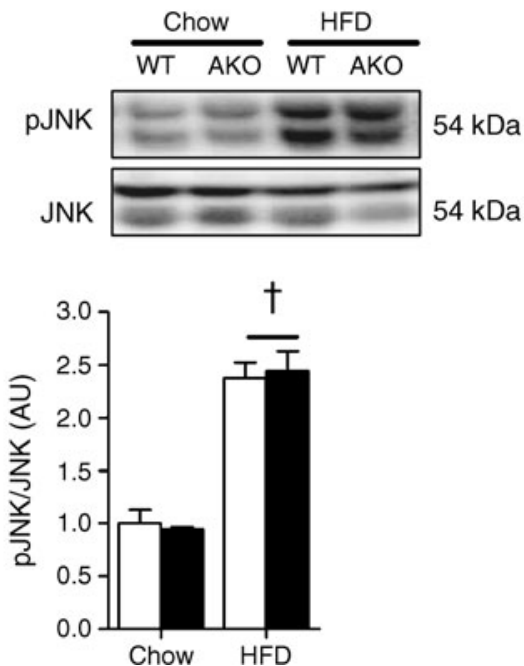

b

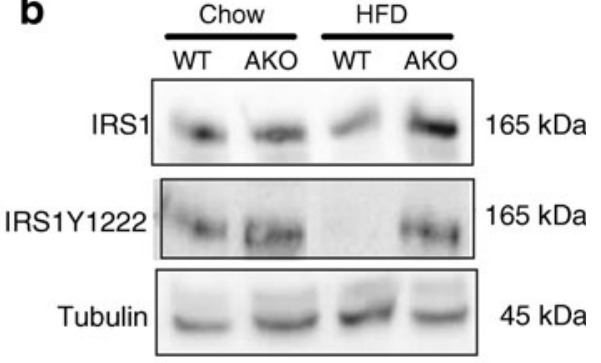

d
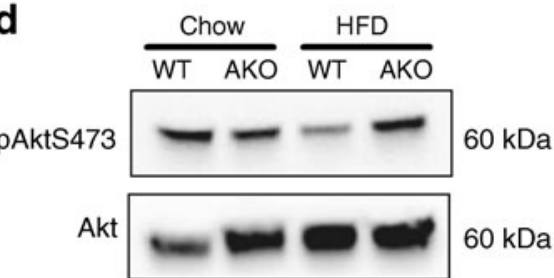
$60 \mathrm{kDa}$

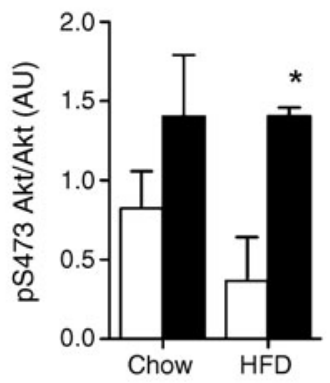

f
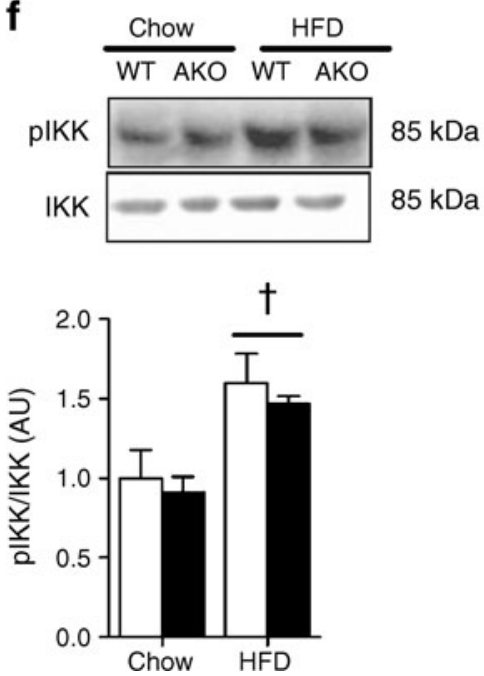

production and phosphorylation in Socs 3 AKO mice resulted in increased Akt T308 and S473 phosphorylation. These data are consistent with previous in-vitro studies, which found that SOCS3 inhibits TNF- $\alpha-$ induced insulin signalling by downregulating both IRS1 production and tyrosine phosphorylation in adipocytes [14]. Importantly, we found that this improvement in adipose tissue insulin sensitivity occurred despite activation of JNK and IKK, suggesting that the inhibition of SOCS3 is sufficient to improve adipose tissue insulin sensitivity independently of alterations in other aspects of inflammatory signalling.

In conclusion, we demonstrate that the inhibition of SOCS3 in adipose tissue of female mice improves glucose tolerance and whole-body insulin sensitivity due to enhanced adipose tissue insulin sensitivity. Importantly, 
improvements in insulin sensitivity occurred independently of changes in body mass, energy balance and adiposity/adipose tissue cell size, findings which are very different from those previously reported following the transgenic overexpression of Socs 3 in adipose tissue [26]. These findings are also in stark contrast to the obesity-promoting effects of Socs 3 deletion in the liver [29]. While these data support an important role for SOCS3 in regulating adipose tissue insulin sensitivity the effects on the IS-GDR were modest. This is consistent with the fact that there was no change in skeletal muscle insulin sensitivity, which quantitatively accounts for a greater percentage of blood glucose disposal than adipose tissue. These data indicate that while SOCS3 is an important negative regulator of adipose tissue insulin signalling, future studies examining the role of SOCS3 in other tissues, such as skeletal muscle, are warranted.

Acknowledgements We thank W. Alexander (Walter and Eliza Hall Institute of Medical Research, University of Melbourne) and B. Kahn (Beth Israel Deaconess Medical Center, Harvard Medical School) for providing us with Socs 3 floxed and aP2-Cre mice, respectively. We are also grateful for the assistance of T. Farncombe and C. Saab from the McMaster Centre for Preclinical and Translational Imaging for completing the CT and PET studies.

Funding These studies were supported by grants and fellowships from the National Health and Medical Research Council, the Diabetes Australia Research Trust, the Canadian Foundation for Innovation and the Canadian Institutes of Health Research (all G. R. Steinberg). S. B. Jorgensen was supported by a Research fellowship from the Danish Medical Research Council (271-05-0697). M. D. Fullerton is a CIHR Banting Postdoctoral Fellow. G. R. Steinberg is a Canada Research Chair in Metabolism and Obesity.

Duality of interest The authors declare there is no duality of interest associated with this manuscript.

Contribution statement RP, MDF, SG, JH, KAH and SBJ researched data. RP, MDF, SG, JH, KAH and SBJ reviewed and edited manuscript. GRS designed experiments and wrote the manuscript. All authors have approved the final version of manuscript.

\section{References}

1. Wormald S, Hilton DJ (2004) Inhibitors of cytokine signal transduction. J Biol Chem 279:821-824

2. Mori H, Hanada R, Hanada T et al (2004) Socs3 deficiency in the brain elevates leptin sensitivity and confers resistance to dietinduced obesity. Nat Med 10:739-743

3. Myers MG Jr (2004) Leptin receptor signaling and the regulation of mammalian physiology. Recent Prog Horm Res 59:287-304

4. Ueki K, Kondo T, Kahn CR (2004) Suppressor of cytokine signaling 1 (SOCS-1) and SOCS-3 cause insulin resistance through inhibition of tyrosine phosphorylation of insulin receptor substrate proteins by discrete mechanisms. Mol Cell Biol 24:5434-5446
5. Steinberg GR, Smith AC, Wormald S, Malenfant P, Collier C, Dyck DJ (2004) Endurance training partially reverses dietaryinduced leptin resistance in rodent skeletal muscle. Am J Physiol Endocrinol Metab 286:E57-E63

6. Steinberg GR, McAinch AJ, Chen MB et al (2006) The suppressor of cytokine signaling 3 inhibits leptin activation of AMP-kinase in cultured skeletal muscle of obese humans. J Clin Endocrinol Metab 91:3592-3597

7. Emanuelli B, Peraldi P, Filloux C et al (2001) SOCS-3 inhibits insulin signaling and is up-regulated in response to tumor necrosis factor-alpha in the adipose tissue of obese mice. J Biol Chem 276:47944-47949

8. Wang Z, Zhou YT, Kakuma T et al (2000) Leptin resistance of adipocytes in obesity: role of suppressors of cytokine signaling. Biochem Biophys Res Commun 277:20-26

9. Ghanim H, Aljada A, Daoud N, Deopurkar R, Chaudhuri A, Dandona P (2007) Role of inflammatory mediators in the suppression of insulin receptor phosphorylation in circulating mononuclear cells of obese subjects. Diabetologia 50:278-285

10. Ghanim H, Abuaysheh S, Sia CL et al (2009) Increase in plasma endotoxin concentrations and the expression of Toll-like receptors and suppressor of cytokine signaling-3 in mononuclear cells after a high-fat, high-carbohydrate meal: implications for insulin resistance. Diabetes Care 32:2281-2287

11. Emanuelli B, Peraldi P, Filloux C, Sawka-Verhelle D, Hilton D, van Obberghen E (2000) SOCS-3 is an insulin-induced negative regulator of insulin signaling. J Biol Chem 275:15985-15991

12. Senn JJ, Klover PJ, Nowak IA et al (2003) Suppressor of cytokine signaling-3 (SOCS-3), a potential mediator of interleukin-6dependent insulin resistance in hepatocytes. J Biol Chem 278:13740-13746

13. Rui L, Yuan M, Frantz D, Shoelson S, White MF (2002) SOCS-1 and SOCS-3 block insulin signaling by ubiquitinmediated degradation of IRS1 and IRS2. J Biol Chem 277:42394-42398

14. Shi H, Tzameli I, Bjorbaek C, Flier JS (2004) Suppressor of cytokine signaling 3 is a physiological regulator of adipocyte insulin signaling. J Biol Chem 279:34733-34740

15. Bjorbaek C, Lavery HJ, Bates SH et al (2000) SOCS3 mediates feedback inhibition of the leptin receptor via Tyr985. J Biol Chem 275:40649-40657

16. Bjorbaek C, El-Haschimi K, Frantz JD, Flier JS (1999) The role of SOCS-3 in leptin signaling and leptin resistance. J Biol Chem 274:30059-30065

17. Howard JK, Cave BJ, Oksanen LJ, Tzameli I, Bjorbaek C, Flier JS (2004) Enhanced leptin sensitivity and attenuation of diet-induced obesity in mice with haploinsufficiency of Socs3. Nat Med 10:734-738

18. Reed AS, Unger EK, Olofsson LE, Piper ML, Myers MG Jr, Xu AW (2010) Functional role of suppressor of cytokine signaling 3 upregulation in hypothalamic leptin resistance and long-term energy homeostasis. Diabetes 59:894-906

19. Bjornholm M, Munzberg H, Leshan RL et al (2007) Mice lacking inhibitory leptin receptor signals are lean with normal endocrine function. J Clin Invest 117:1354-1360

20. Wang MY, Orci L, Ravazzola M, Unger RH (2005) Fat storage in adipocytes requires inactivation of leptin's paracrine activity: implications for treatment of human obesity. Proc Natl Acad Sci U S A 102:18011-18016

21. Wang MY, Lee Y, Unger RH (1999) Novel form of lipolysis induced by leptin. J Biol Chem 274:17541-17544

22. Orci L, Cook WS, Ravazzola M et al (2004) Rapid transformation of white adipocytes into fat-oxidizing machines. Proc Natl Acad Sci U S A 101:2058-2063

23. Gaidhu MP, Anthony NM, Patel P, Hawke TJ, Ceddia RB (2010) Dysregulation of lipolysis and lipid metabolism in visceral and 
subcutaneous adipocytes by high-fat diet: role of ATGL, HSL, and AMPK. Am J Physiol Cell Physiol 298:C961-C971

24. Gauthier MS, O’Brien EL, Bigornia S et al (2010) Decreased AMP-activated protein kinase activity is associated with increased inflammation in visceral adipose tissue and with whole-body insulin resistance in morbidly obese humans. Biochem Biophys Res Commun 404:382-387

25. Krebs DL, Hilton DJ (2001) SOCS proteins: negative regulators of cytokine signaling. Stem Cells 19:378-387

26. Shi H, Cave B, Inouye K, Bjorbaek C, Flier JS (2006) Overexpression of suppressor of cytokine signaling 3 in adipose tissue causes local but not systemic insulin resistance. Diabetes 55:699-707

27. Jamieson E, Chong MM, Steinberg GR et al (2005) Socs1 deficiency enhances hepatic insulin signaling. J Biol Chem 280:3151631521

28. Torisu T, Sato N, Yoshiga D et al (2007) The dual function of hepatic SOCS3 in insulin resistance in vivo. Genes Cells $12: 143-154$

29. Sachithanandan N, Fam BC, Fynch S et al (2010) Liver specific SOCS3 deletion in mice enhances hepatic insulin sensitivity and lipogenesis resulting in fatty liver and obesity. Hepatology 52:1632-1642

30. Kiu H, Greenhalgh CJ, Thaus A et al (2009) Regulation of multiple cytokine signalling pathways by SOCS3 is independent of SOCS2. Growth Factors 27:384-393

31. Abel ED, Peroni O, Kim JK et al (2001) Adipose-selective targeting of the GLUT4 gene impairs insulin action in muscle and liver. Nature 409:729-733

32. Galic S, Fullerton MD, Schertzer JD et al (2011) Hematopoietic AMPK betal reduces mouse adipose tissue macrophage inflammation and insulin resistance in obesity. J Clin Invest 121:4903-4915

33. O'Neill HM, Maarbjerg SJ, Crane JD et al (2011) AMP-activated protein kinase (AMPK) beta1beta2 muscle null mice reveal an essential role for AMPK in maintaining mitochondrial content and glucose uptake during exercise. Proc Natl Acad Sci U S A 108:16092-16097

34. Dzamko N, Vandenderen BJ, Hevener AL et al (2010) AMPK $\beta 1$ deletion reduces appetite preventing obesity and hepatic insulin resistance. J Biol Chem 285:115-122

35. Saab C, Labiris N, Chirakal R, Farncombe T (2007) A database of normal PET and SPECT radiotracer distributions in rats and mice. J Nucl Med Meeting Abstracts 48:292P-b-
36. Watt MJ, Dzamko N, Thomas WG et al (2006) CNTF reverses obesity-induced insulin resistance by activating skeletal muscle AMPK. Nat Med 12:541-548

37. Chen Z-P, McConell GK, Michell BJ, Snow RJ, Canny BJ, Kemp BE (2000) AMPK signaling in contracting human skeletal muscle: acetyl-CoA carboxylase and NO synthase phosphorylation. Am J Physiol 279:E1202-E1206

38. Maeda K, Cao H, Kono K et al (2005) Adipocyte/macrophage fatty acid binding proteins control integrated metabolic responses in obesity and diabetes. Cell Metab 1:107-119

39. Jiang C, Qu A, Matsubara T et al (2011) Disruption of hypoxiainducible factor 1 in adipocytes improves insulin sensitivity and decreases adiposity in high-fat diet-fed mice. Diabetes 60:2484-2495

40. Wueest S, Rapold RA, Schumann DM et al (2010) Deletion of Fas in adipocytes relieves adipose tissue inflammation and hepatic manifestations of obesity in mice. J Clin Invest 120:191-202

41. Kumar A, Lawrence JC Jr, Jung DY et al (2010) Fat cell-specific ablation of rictor in mice impairs insulin-regulated fat cell and wholebody glucose and lipid metabolism. Diabetes 59:1397-1406

42. Hirosumi J, Tuncman G, Chang L et al (2002) A central role for JNK in obesity and insulin resistance. Nature 420:333-336

43. Gao Z, Hwang D, Bataille F et al (2002) Serine phosphorylation of insulin receptor substrate 1 by inhibitor kappa B kinase complex. J Biol Chem 277:48115-48121

44. Croker BA, Krebs DL, Zhang JG et al (2003) SOCS3 negatively regulates IL-6 signaling in vivo. Nat Immunol 4:540-545

45. Galic S, Oakhill JS, Steinberg GR (2010) Adipose tissue as an endocrine organ. Mol Cell Endocrinol 316:129-139

46. Bence KK, Delibegovic M, Xue B et al (2006) Neuronal PTP1B regulates body weight, adiposity and leptin action. Nat Med 12:917-924

47. Shi H, Kokoeva MV, Inouye K, Tzameli I, Yin H, Flier JS (2006) TLR4 links innate immunity and fatty acid-induced insulin resistance. J Clin Invest 116:3015-3025

48. Arnold SF, Obourn JD, Jaffe H, Notides AC (1995) Phosphorylation of the human estrogen receptor on tyrosine 537 in vivo and by src family tyrosine kinases in vitro. Mol Endocrinol 9:24-33

49. Leong GM, Moverare S, Brce J et al (2004) Estrogen up-regulates hepatic expression of suppressors of cytokine signaling-2 and -3 in vivo and in vitro. Endocrinology 145:5525-5531

50. Ribas V, Nguyen MT, Henstridge DC et al (2010) Impaired oxidative metabolism and inflammation are associated with insulin resistance in ERalpha-deficient mice. Am J Physiol Endocrinol Metab 298:E304-E319 